\title{
Diurnal variation of surface electric field at a tropical station in different seasons: a study of plausible influences
}

\author{
R. Latha \\ Indian Institute of Tropical Meteorology, Pune-411008, India \\ (Received September 2, 2003; Revised December 5, 2003; Accepted December 18, 2003)
}

\begin{abstract}
Based on the fair weather days of 1993 surface electric field at Pune (18 32 N, 7351 E, 550 m ASL) is studied for its diurnal and seasonal variations. The analysis attempts to look into factors like atmospheric pollution and space charge formation in presence of the meteorological factors prevalent in the three seasons that modify the global effects that govern fair weather electric field at the site of measurement. Summer (FMAM), monsoon (JJAS) and winter (ONDJ) are the seasons considered. By and large diurnal variation is with double oscillation. The results show high persistent value of electric field during monsoon. Evening peak is the highest during winter with high atmospheric stability conditions and summer afternoons have the lowest value. Space charge formation depending on the wetness or dryness of the ground is proposed in connection with the high and low values of electric field close to ground. It appears that space charge is equally or more important in contributing to electric field variations as conductivity as for local effects. The generation of positive space charge occurrence in connection with evaporation and negative space charge occurrence with very dry ground bypassing the local component to global one due to large area coverage elsewhere as well, under similar weather conditions are suggested. Possibility of monsoon field showing a glimpse of global activities being a cleaner tropical environment during this period is also discussed. Observational verification of space charge formation and the role it could be playing, on abundantly available, by the then active physical processes plays on thunderstorm electrification based on convective theory is mooted.
\end{abstract}

Key words: Atmospheric stability, atmospheric aerosols, sunrise peak, evening peak.

\section{Introduction}

Electric field measured at the earth's surface is time and again ascertained as one of the major sources of information in studies of atmospheric electricity, be it global, regional or local. Devoid of local effect this measure would provide an actual mapping of Ionospheric potential variation, the positive electrode of Global Electric circuit (GEC). Potential of equalization layer, local atmospheric conductivity and space charge density close to ground determine magnitude of surface electric field $(E)$ at any place. Hence diurnal variation curve of $E$ will have a predictable shape depending on the place of measurement.

Wilson (1920) hypothesized that potential of equalization layer as measured on earth under fair weather region is the summative effect of the global disturbed weather feedback. Williams and Heckman (1993) considered lightning, point discharge, conduction and precipitation currents as the feedback charge transfer pathways in analyzing foul weather. They concluded with a note that conduction current other than lightning is the dominant charger for the earth's surface. However, long term measurements over the ocean, the Carnegie curve is globally accepted to reflect the ionospheric potential is with single oscillation, has maximum 18-21 hrs GMT and the minimum at about 3-4 hrs GMT, in phase with global thunderstorm frequency curve. $E$ follows the same pattern over cleaner land stations such as Antarctica

Copy right(C) The Society of Geomagnetism and Earth, Planetary and Space Sciences (SGEPSS); The Seismological Society of Japan; The Volcanological Society of Japan; The Geodetic Society of Japan; The Japanese Society for Planetary Sciences. or mountaintops. Tropics' being the major source of lightning and any meteorological phenomenon is a cycle in itself, any fair weather study here might prove a valuable connection for the rest of the cycle. The present study conducted at Pune might well be considered as of a representative tropical station, experiencing average meteorological conditions that are typical of the tropics.

Various earlier studies have reasoned out the diurnal behaviour of $E$. According to Brown's hypothesis (1935), local diurnal variation curve of $E$ of double oscillation over land surface would be the resultant of a single 24-hour fluctuation superimposed by a depression around noon (due to convection). Israel (1948) attributes variation of local electric field to resistivity of lower atmospheric layer. As small ions practically determine the local conductivity, it will depend upon the rate of production of small ion and recombination with ions of opposite sign or attachment with bigger particles. Franke (1949) mathematically proved that the diurnal variation of the $E$ would generally be a curve with double oscillations following vertical atmospheric mass exchange over land. Muhleisen (1956) has experimentally dealt with the effect of presence of water in different forms and condensation nuclei on atmospheric potential to a great extent. The 'Sunrise Effect' observations of $E$ by Law (1963) showed that space charge and $E$ appears to be more closely related to each other than to any other variable. Marshall et al. (1999) studied the 'Enhanced Sunrise Effect' to show that it does not contain to the layers close to ground and nearness to water bodies significantly elevates the values reached. Of recent 


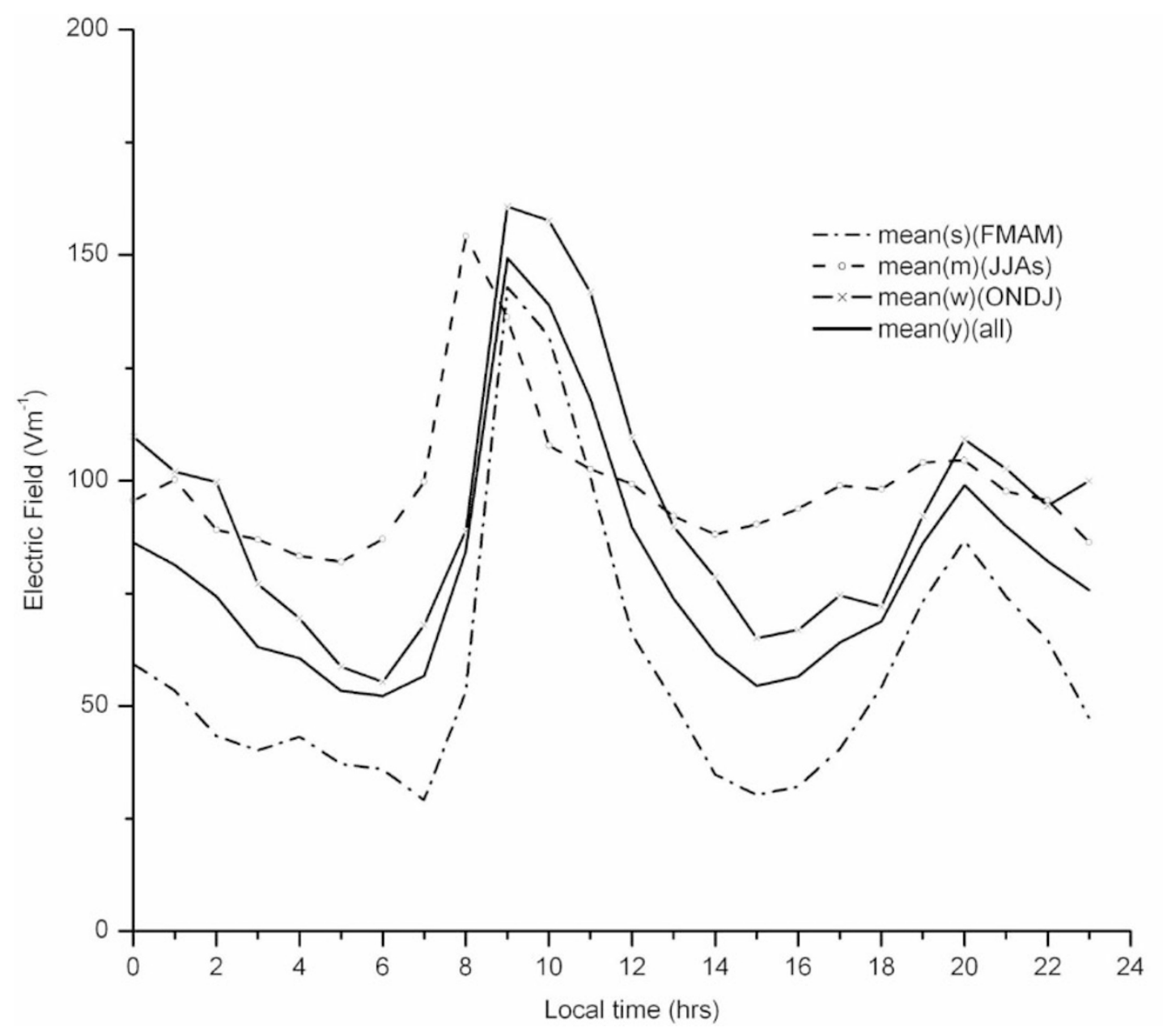

Fig. 1. Diurnal variation of Surface Electric Field $(E)$ : all seasons' (FMAM for summer, JJAS for monsoon and NDJF for winter) comparison.

a school of thought (Delgado et al., 2003) is evolving that it is not the $E$ that is controlled by pollution dependent conductivity but the pollutants rearrange themselves as per the prevalent $E$ depending on their dipole moment. It could be very well concluded that atmospheric ions and charged nuclei and their interaction in presence of various meteorological parameters give rise to local component of $E$ of atmosphere. However, which electrical parameter forms the primary factor in deciding the magnitude of $E$ is yet not clear.

Despite of the origin, the effect of meteorological parameters on the variation of $E$ is of importance. While considering a season similar meteorological conditions continue to exist for a considerable period. Further a 24-hour cycle is the most primary cycle for any atmospheric electric parameter. Hence diurnal variation of $E$ in different seasons is of prime importance in deciding electrical climate at a place or similar place or a region where the meteorological conditions are similar.

\section{Instrumentation and Observations}

In this paper an attempt is made to analyze diurnal and seasonal variations of $E$ on fair weather days of the year 1993 with reference to local conditions prevailing at Pune (18 $32 \mathrm{~N}, 7351 \mathrm{E}, 550 \mathrm{~m} \mathrm{ASL})$ as a typical instance of a tropical semi-urban station. The site of observation is described elsewhere (Kamra, 1982). However, there are no sources of direct pollution in the vicinity.

The $E$ is measured with an a.c field mill placed in a pit with its sensor plate positioned flush with ground. The a.c field mill has a sensitivity of $5 \mathrm{v} / \mathrm{m}$ and an accuracy of 5\%. A weather post located about $40 \mathrm{~m}$ away from the field mill in the observatory connected to a datalogger recorded the meteorological parameters, wind speed and direction, dry and wet bulb temperatures all along. Seasonal variation of polar conductivity and ion concentration has been studied by Dhanorkar and Kamra (1993) at this observatory. Further multiple studies of space charge density variation have also been carried out earlier (Kamra, 1982; Pawar and Kamra, 2000) here. Weather conditions on visual observation were also recorded manually. Daily maintenance of instrument included cleaning, offset and power supply check and calibration constant verification. Several workers have studied Sapsford (1937), Kamra (1969), Harrison (2003), Harrison and Alpin (2002) essentially $E$ and drawn various conclusions such as effect of atmospheric pollution, wind, fallout of radioactive emission and smoke concentration.

For the analysis a 'Fair Weather Day' is considered as the day with less than 3 octa cloud cover, wind speed less than 4 $\mathrm{m} / \mathrm{s}$ and no precipitation. The observations were taken at 1 min. interval averaged over an hour. Positive potential gradient or negative electric field exists in the positive $z$ direction for fair weather is the sign convention followed. 


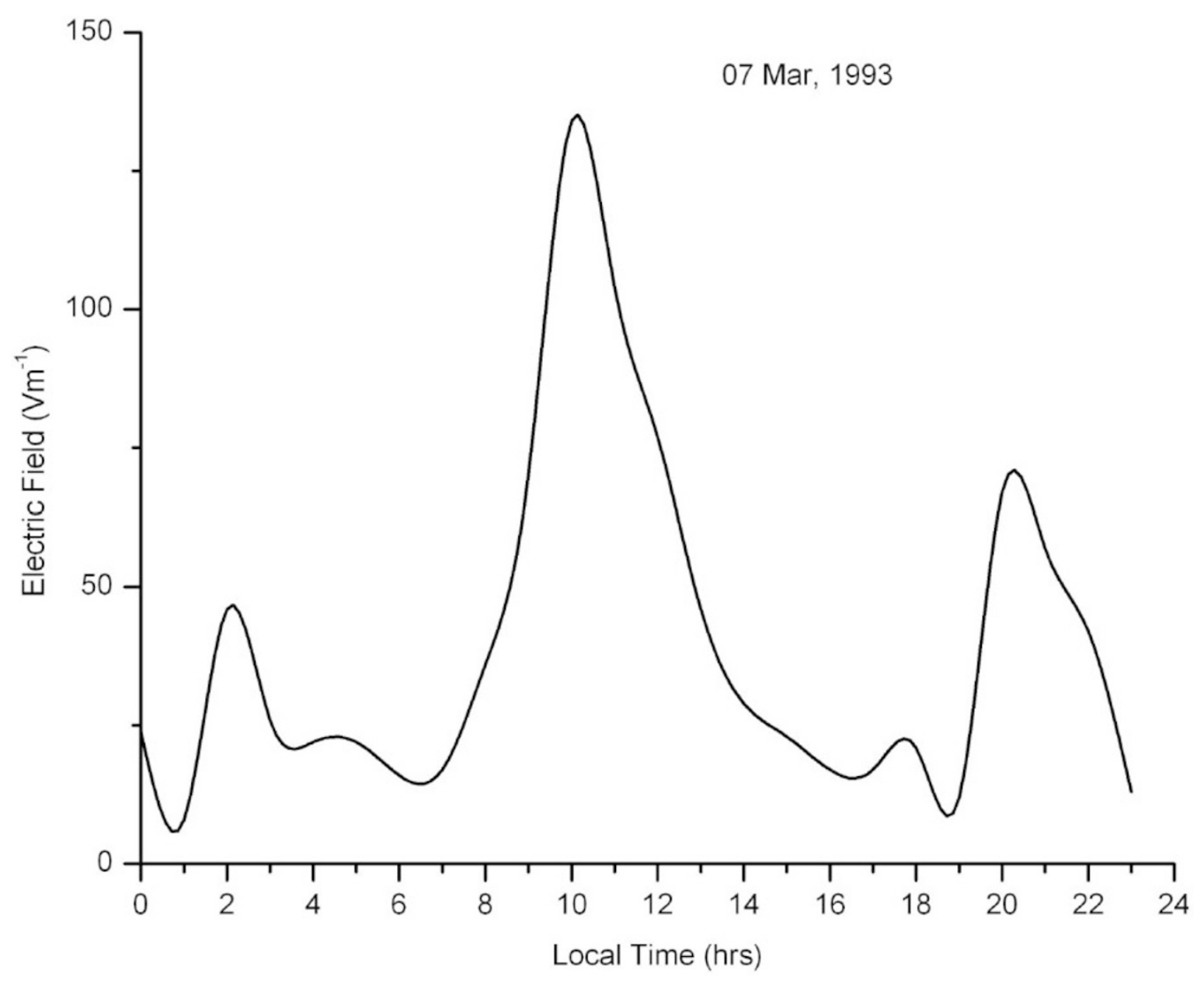

Fig. 2. Diurnal variation of $E$ on a typical day of summer (7 Mar., 1993).

For the graphs absolute value of $E$ is considered.

The data is divided to represent the three seasons experienced here viz. 'Summer, Monsoon and Winter'. Summer season is experienced from Feb-May (FMAM), monsoon or rainy season spreads over June-Sept (JJAS) and winter falls from Oct-Jan (ONDJ). Summer is hot around $37^{\circ} \mathrm{C}$ during day time with considerable wind speed. Westerly airflow with an influx of moisture from the Arabian Sea dominates in monsoon season with intermittent/light continuous rains. October onwards a week easterly flow sets in with minimum temperature below $10^{\circ} \mathrm{C}$. Morning haze is recurrent during this period.

In some of the earlier investigations on potential gradient variation, the divisions considered were summer, winter and equinoxes as in the case of Israel (1973), Kamra (1969) or pre and post monsoons, monsoon and winter of Kanadalgaonkar and Manohar (1991). This study considers summer, monsoon and winter as the representative seasons as Indian region experiences four months long rainy season, therefore cannot be overlooked and winter-summer divisions are good enough for in the case of fair weather days.

\section{Results and Discussions}

Figure 1 shows the average seasonal and annual diurnal variation of $E$. It is clear from this plot that,
1) All the curves show a bimodal variation with a sunrise peak and an evening peak. Two minima can also be seen (early morning and afternoon). Sunrise peak occurs between 7-10 hrs and evening peak at around 19-21 hrs.

2) Annual curve of $E$ falls between summer and winter curves.

3) The curve for summer has the least value for afternoon minimum. It has got the sharpest slope of rise for the sunrise peak.

4) The monsoon curve maintains the highest average value of $E$. During this season, sunrise peak occurs at the earliest and it also settles to the daytime value very soon. Afternoon reduction in field value is quite minimal and evening peak is not well pronounced.

5) Winter curve appears to be closely followed by the annual diurnal variation. It is during winter that the sunrise peak settles with the slowest pace but peaking in the evening is the sharpest and highest of all.

Single oscillation of diurnal variation of $E$ is mainly observed over sea, the Carnegie curve, depicting the global thunderstorm activity. Similar variation is observed over Arctic and Antarctic stations (Israel, 1973) and Eskdalemuir 


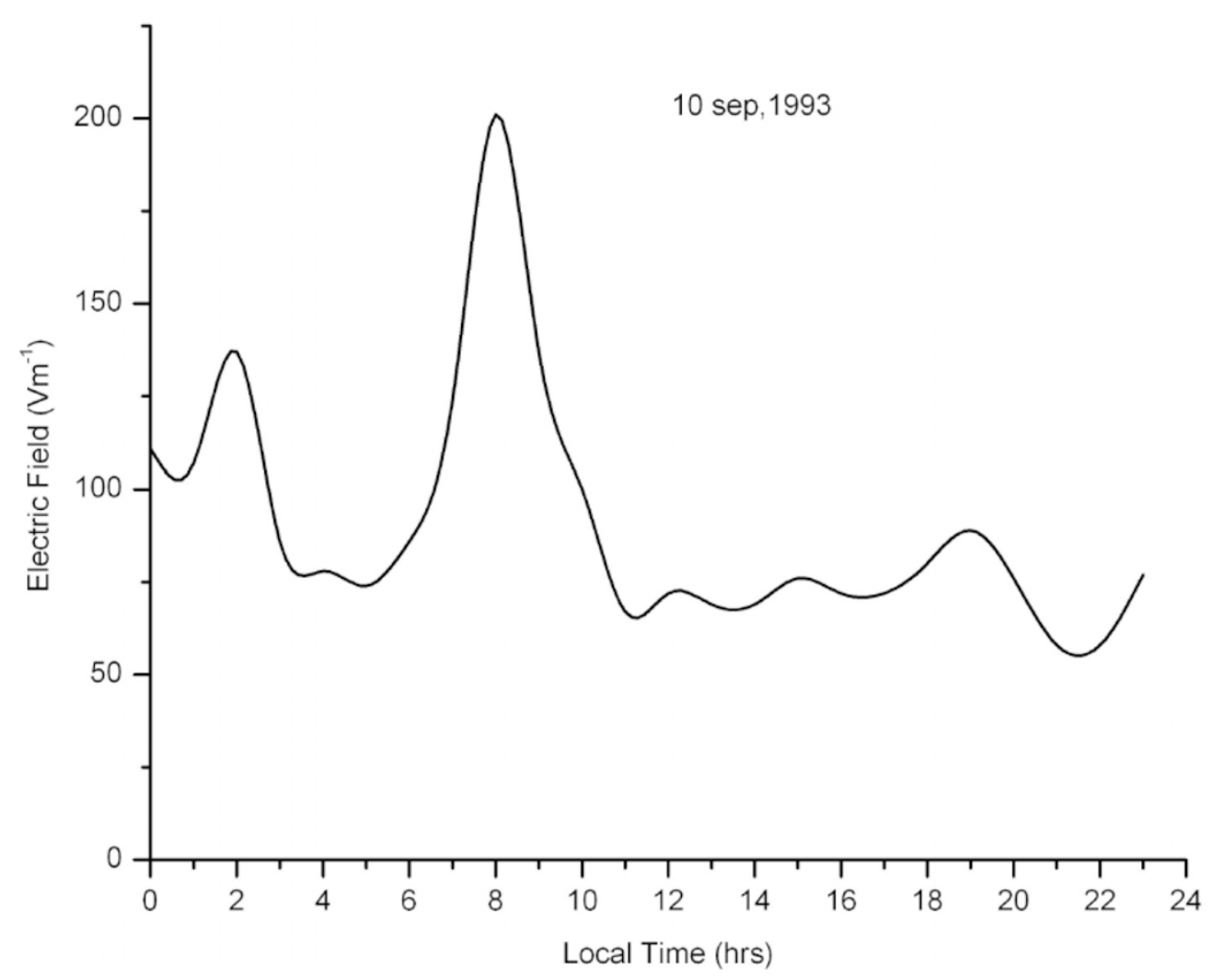

Fig. 3. Diurnal variation of $E$ on a typical day of monsoon (10 Sep., 1993).

as reported by Harrison (2003). Here the land stations have pristine air qualities. Bimodal variation of diurnal curve of $E$ (Fig. 1) is well in place with earlier observations over land stations (Chalmers, 1967). Israel (1973) refers to bimodal variation of $E$ over land station such as Tokyo, Baudung and so on. Kandalgaonkar and Manohar (1991) during their long term study of $E$ (1930-1987), in the same station at a different site, obtained a similar diurnal pattern. The results of their study showed a gradual increase in $E$ values over the years along with the increase in Angstrom Turbidity Coefficient, as an indicator of increased pollution. Long term diurnal variation study of $E$ at Kew observatory (Harrison, 2003) also follows the bimodal variation; with almost identical the time of occurrence of sunrise and evening peak with the present results, except for higher values of $E$, as their LMT and GMT has very little difference. While various theories behind diurnal variation of $E$ is described in the introduction, it is felt that variation of resistivity of lower layer of atmosphere due to various factors such as 1) changes in vertical convection 2) ions of various size ranges 3) aerosol content variation affecting them and 4) space charge formation due to different reasons are the determinants.

The morning maximum, 'Sunrise peak' has been studied in detail by many investigators (Kasemir, 1956; Chalmers, 1967) the start of convection and upward transport of lowlying electrode layer charge and hence space charge related enhancement in electric field. Law's (1963) observation of the 'sunrise effect', increase in $E$, has shown that, is coincident with increase in positive charge density and breakdown of nocturnal inversion with no alteration in conductivity. Dhanorkar et al. (1989) and Kamra (1982) has observed the same effect here. However, unlike certain other observations (Tammet and Israelsson, 2001) sunrise peak observed at this place is more intense. Nearness to water bodies may have an enhanced sunrise effect as explained by Marshall et al. (1999) but the nearest water body here is about more than $2 \mathrm{~km}$ away. It is well established that under the state of electrical equilibrium electrical conductivity is inversely proportional to aerosol concentration. The reduction in conductivity thus caused and to have air earth current maintained, in turn increases $E$. This explains the pollution related increase in $E$. Previous studies of Dhanorkar and Kamra (1993) clearly indicate the reduction in conductivity around 9 LMT. Further observations of Dhanorkar and Kamra (1994) show peak ionization rate close to ground early in the morning accompanied by increase in total aerosol concentration. Conclusively the source of aerosol injection has to be the morning rush hour of traffic almost simultaneous the time of occurrence of sunrise peak thereby forming an additional factor for enhancement in $E$. Evidenced by the stability study of Saha and Anathakrishnan (1976) earlier, this station experiences reversal of lapse rate occurring in the morning and evening, throughout the year. This changeover explains the little delay in sunrise peak experienced here.

Evening maximum experienced perennially here similar to many other land stations is rooted on to the lowering of exchange layer heights that has its maximum in the afternoon. Raj et al. (1997) studied the aerosol column content in the vicinity and found that about this time wind speed and convection reduces drastically and aerosol subsidence to the lower layers accelerates resulting in an intense layer above ground level. As explained earlier, reduction in conductiv- 


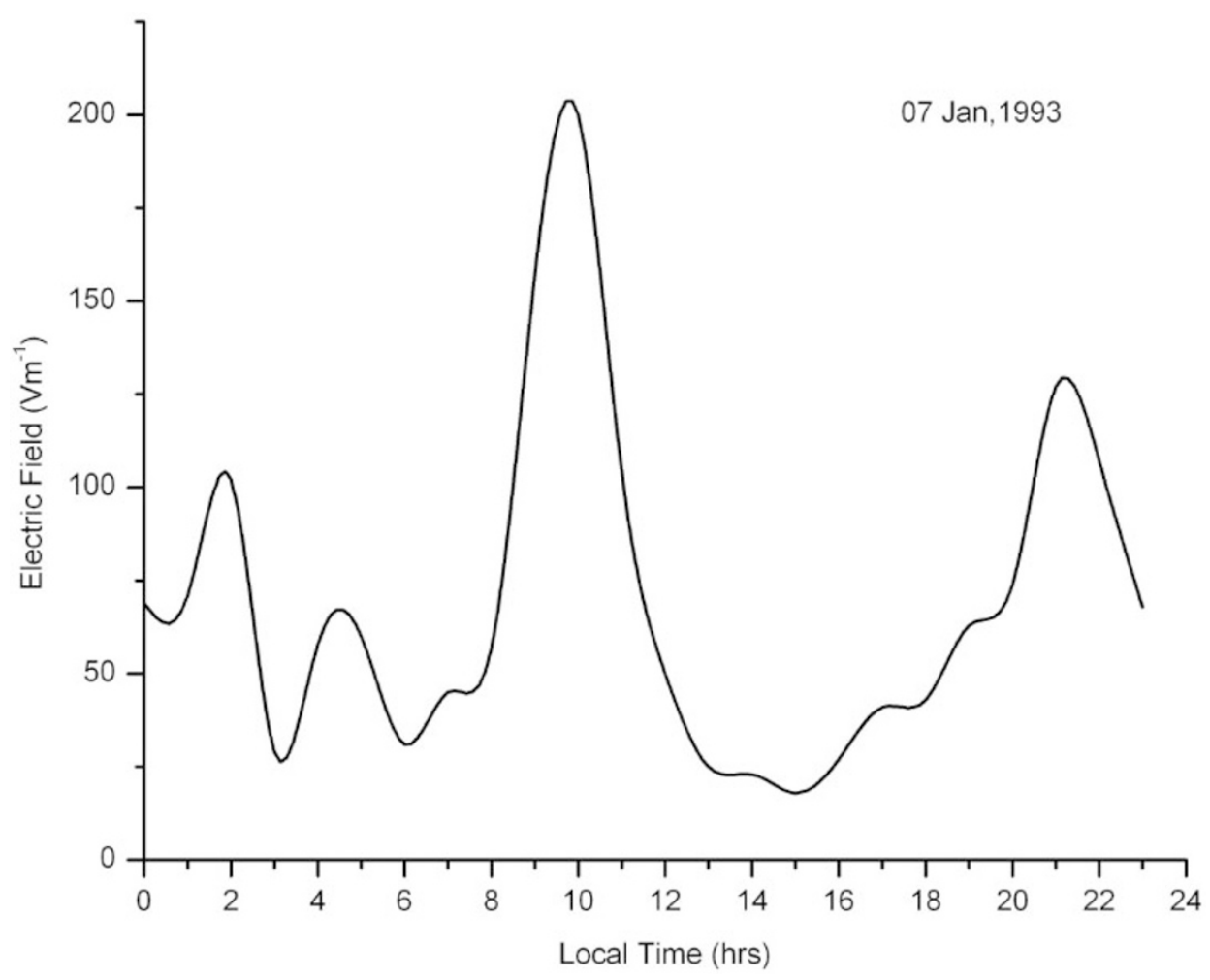

Fig. 4. Diurnal variation of $E$ on a typical day of winter (7 Jan., 1993).

ity in this layer results in increased field values. Observation of Dhanorkar and Kamra (1993) shows another conductivity minimum about 19 LMT is supports the same.

The studies of Mani and Huddar (1972) for comparing the change in surface aerosol and electrical parameters, at Poona between 1935-1937 and 1967-1969 showed the relation between conductivity and aerosol concentration are though proportional is not linear. The change of their measurement site during the study period in 1967 brought about 10 times more aerosol concentration, it resulted in decrease of conductivity only by $61 \%$ and the average electric field increase was $13 \%$. Similarly, observations at this site though show reduction of conductivity, makes the author skeptical to that, is insufficient to justify such an increase in the $E$ value. Observations of Pawar and Kamra (2000), during the study to compare different methods of measurement of space charge, at this station, show that the space charge tube placed at a height of $0.1 \mathrm{~m}$ above ground level indicates increase in positive space charge around $18 \mathrm{hrs}$. This specifically occurs whenever there is non-zero wind speed immediately after sunset as is the case generally throughout the year. However, this remains as an unexplained observational fact to be looked into. Space charge in turn will raise the $E$ by direct action of Poisson's equation. In order to produce a change in $E$ of $1 \mathrm{~V} / \mathrm{m}$ in $1 \mathrm{~m}$ there must be a space charge of 8.8 $\mathrm{pC} / \mathrm{m}^{3}$ (Chalmers, 1967). The referred observations indicate an increase in space charge roughly about $50 \mathrm{pC} / \mathrm{m}^{3}$ for a prevailing wind speed of $0.5 \mathrm{~m} / \mathrm{s}$. Moreover, global activity of thunderstorms, intense during 14-19 hrs GMT (19.30$0.30 \mathrm{hrs}$ locally) may also be contributing to the increase in $E$, possibly quite insignificantly.
Earlier observational results (Dhanorkar et al., 1989; Kamra, 1982; Pawar and Kamra, 2000) indicate the presence of nocturnal stability, high negative space charge and conductivity during nighttime resulting in suppressed or at times negative $E$. In the present study average curves indicate higher fluctuation with suppressed values. The appearance of annual curve of $E$ in between that of summer and winter is for the fact that these seasons have more representation in the case of fair weather days, by the law of averages.

Lower values for $E$ in summer than winter is consistent with (Tammet and Israelsson, 2001; Kandalgaonkar and Manohar, 1991; Chalmers, 1967). However, the results are to be carefully interpreted in this region that experiences four months long 'summer monsoon'. In this study though FebMay are taken as summer months, the period (Jun-Sept) the northern hemisphere summer is considered under the monsoon season. Occurrence of a late morning minimum, just after sunrise points out should be the outcome of increasing temperature inversion occurring in the early morning and continues a little further to sunrise than other seasons (Saha and Anathakrishnan, 1976), but the sharp increase to high could be attributed to the sudden solar influx with low relative humidity. Though one could expect sunrise peak of summer slightly earlier than in winter, the averaging for one hour has failed to pinpoint the timing. Settling in steps to lower values might be controlled by turbidity of the atmosphere.

The most interesting feature of summer curve is the very low afternoon values (Fig. 1). The summer afternoon atmosphere is doubtlessly in the well-mixed condition and the winds are also comparatively high. Kamra (1968) explained the effect of high winds on reduction, at times reversal of the $E$. This is especially true when wind speed is high enough 


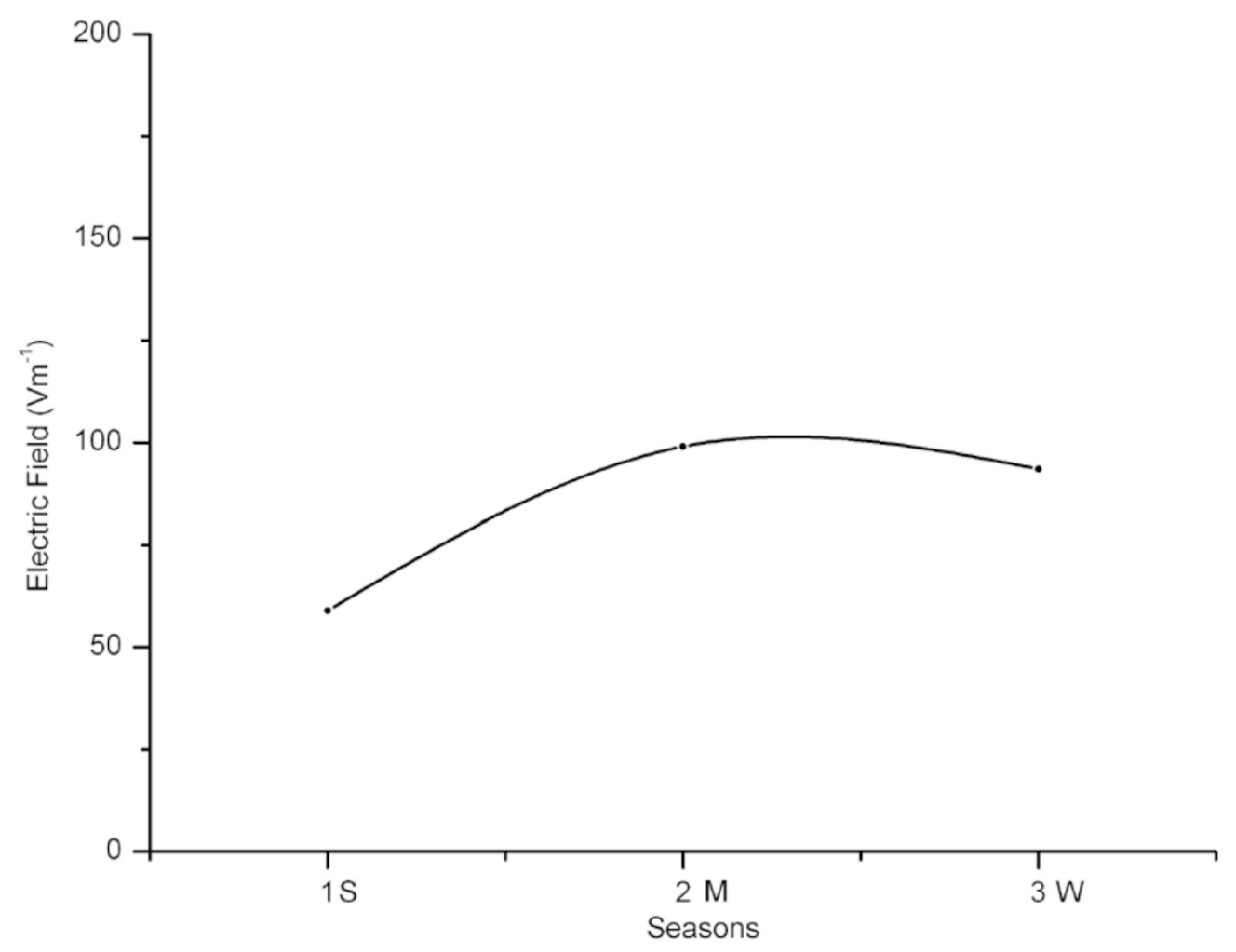

Fig. 5. Annual variation of $E$ through seasonal averages; seasons: FMAM for summer, JJAS for monsoon and NDJF for winter.

to raise fine layer of sand at the ground level. He has supported Coffman's (1963) suggestion of electron affinity of silicon dioxide for negative space charge generation during sand/dust raising wind. It was confirmed again by Israelsson (1994a) that moderate to high wind over very dry ground facilitates negative space charge generation near to ground. He reasoned out this phenomenon to be the electrification of ground level air to selective ionization arising out of temperature gradient formation. A space charge density measurement intended to study seasonal variation planned further should give a clearer picture. Stability is attained at later hours in summer than in winter but the level of inversion is higher than in monsoon. A typical day's variation of electric field is shown in Fig. 2.

The air is cleaner due to wash out of aerosol particles by rains in the monsoon season. Stability studies of Saha and Anathakrishnan (1976) indicates lowest level of inversion during monsoon earliest return to normal. This anchors an early sunrise peak, so also the quick settling of $E$ to steady values. Vehicular pollution though present in the same as any other season, as stated by Anderson (1982) the pollutants discharged into a well-mixed region disperse throughout very fast, do not cause a large effect. Monsoon curve of variation of $E$ is unique in nature (Fig. 1); with lower aerosol content and non-significant conductivity variation it is expected to have low values of $E$ comparatively. However, after the morning peak sets down to the normal value it remains more or less the same with hardly any reduction throughout the afternoon. Figure 3 explicitly shows this behavior. The enhancement in $E$ can be explained by the generation of positive space charge acting upon during periods of high evaporation from the ground. Muhleisen (1958) had put forward a hypothesis for such behavior of $E$ in the case of evaporation from wet ground surface. Observations of Israelsson (1994b) prove the positive space charge production on evaporation from wet surface. During monsoon season the ground remains wet due to intermittent rains and the black soil here retains it for a longer time as well. This situation facilitates quite an amount of evaporation during afternoon hours. Appreciable wind in the afternoons furthers this process and resulting space charge. Pure evaporation inside a room do not cause any charge production but as explained by Israelsson (1991) evaporation from wet ground gives rise to a temperature gradient in the lowest layer above the wet ground. This possibly causes a thermochemical electro-potential that favors unequal attachment of small ions. Seasonal variation of conductivity at this observatory (Dhanorkar and Kamra, 1993) does not show any significant change during day time conductivity values. This further supports the proposal of space charge formation as the cause of higher $E$ in monsoon. Lesser concentration of aerosol and comparatively quicker dispersion of effluents in the evening hours might undoubtedly hold the key for suppressed evening high.

Alderman and Williams (1996) have established that maximum of potential gradient should coincide with the northern hemisphere summer while seasonal variations of GEC are considered. The high average value of $E$ occurring here in Jun-Sept might be showing some influence of global activities. A closure look at the monsoon curve indicates a clear, but not well pronounced high at the time of global peak i.e., $19 \mathrm{hrs}$ GMT or around $1 \mathrm{hr}$ LMT. Observation of aerosol column content here though shows a drastic reduction to about $50 \%$ of that in the winter (Raj et al., 1997) is quite higher than the accepted cleaner environment good enough to mask 


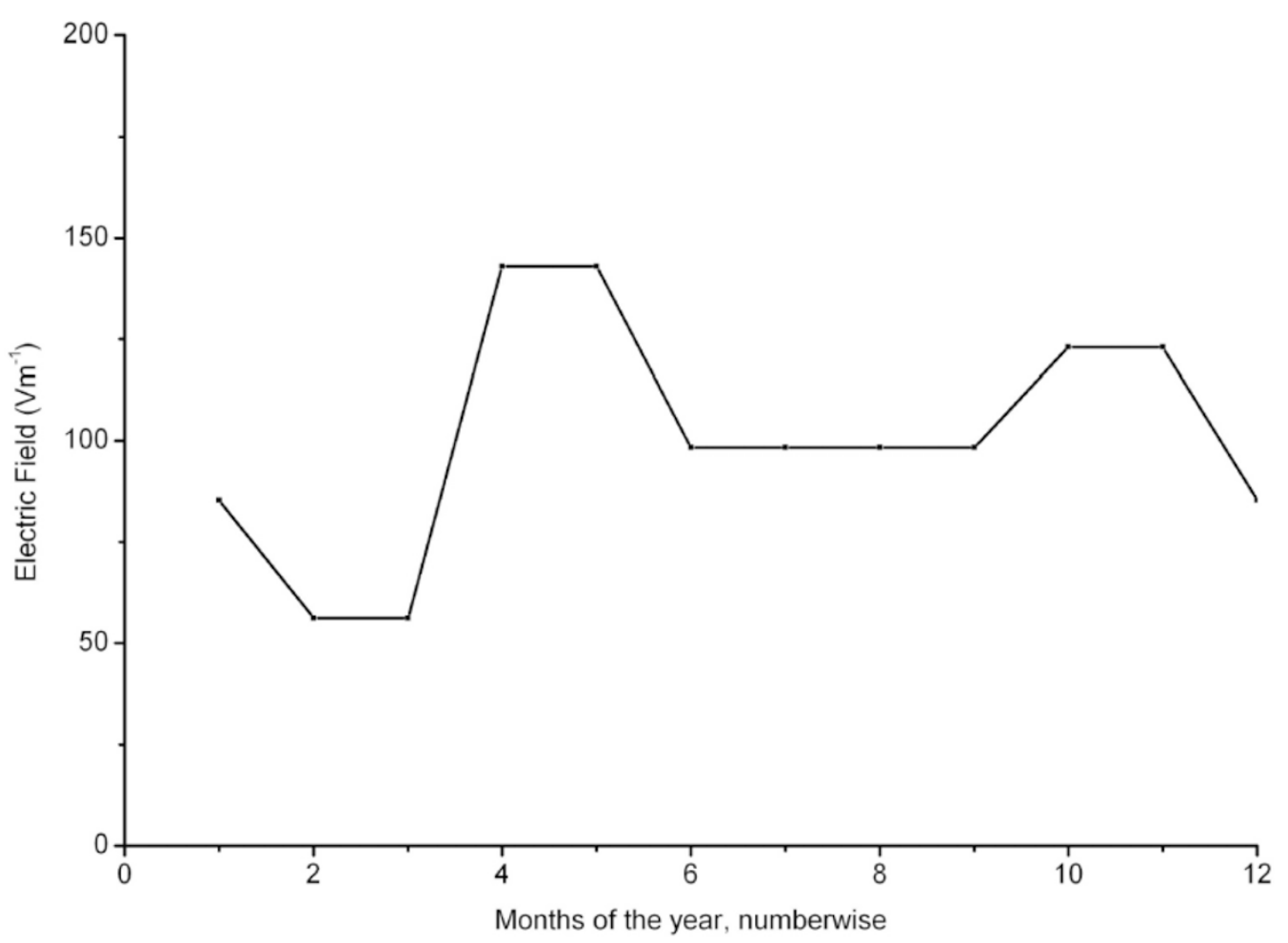

Fig. 6. Annual variation of $E$ through seasonal averages; seasons: JD for winter, FM for summer, AM for pre-monsoon, JJAS for monsoon and ON for post-monsoon.

any global changes. Though monsoon period is the cleanest of all seasons, as observed by Williams et al. (2002) at Amazon region, the aerosol concentration must surely vary during raining and nonraining (break) period. As the present study is essentially a fair weather study rainy days are not included and aerosol concentration measurements available are of average values.

Diurnal variation of $E$ in winter reduces to single oscillation curve in many land stations but at this station diurnal variation is bimodal (Fig. 1). Columnar resistance or space charge whatever may be controlling the local $E$; it is convection that decides the part it should be playing. In many land stations at higher latitudes the want of appreciable convection holds the key for single oscillation. Nocturnal high stability set into the lower layers and the temperature inversion experienced here (Saha and Ananthakrishnan, 1976) ensures the morning maximum during winter as well. Reduced rate of increase in vertical mixing slows down the return of $E$ to its daytime values. Though the values tend to decrease in the afternoon hours the process is restricted because of the early fall in temperature as a result of which free convection is inhibited. A point worth mentioning regarding the year under consideration is that there were some rainy days even in the month of December, an unusual event. This occurrence could have an influence in retaining the afternoon values to a higher level as this causes evaporation from wet ground. However, the evening maximum is well pronounced. The study of seasonal variation of aerosol loading exhibit a maximum in the winter months (Raj and Devara, 1990) at this station result in the reduction of conductivity raises the $E$ value undoubtedly. Considering the calm atmospheric conditions of atmosphere prevail at that time one could even expect an early evening peak (Fig. 4). Here again, non-wellmixed atmosphere, denser aerosol resulting in lower conductivity should have forced $E$ to remain high, but the aforementioned increase in conductivity (Dhanorkar and Kamra, 1994) due to radioactive ionization definitely appears to limit $E$ values and cause high night time fluctuation and this effect is (Dhanorkar and Kamra, 1993) at its maximum in winter. Recurrence of the same is reiterated in a recent study elsewhere (Prasad et al., 2003).

Figure 5 displays annual variation of $E$ drawn along seasonal averages. Here the designated summer months show the least $E$ value, increasing to the highest during monsoon and reducing thereafter in winter. The fore-mentioned grouping of months are the simplest possible for analysis. A little deeper probing require further divisions as this could bring better information. In Fig. 6 the curves are redrawn with Jan. and Dec. (JD) for winter, Feb. and Mar. (FM) for 'undisturbed' summer. Apr. and May (AM) and Oct. and Nov. (ON) are the pre-monsoon and post-monsoon period respectively with a lot of thunderstorms. The monsoon season is from Jun-Sept (JJAS). Apr. and May are periods with high temperature, intense thunder activities and at times very heavy downpours whereas Oct. and Nov. are months with not so high temperatures, slightly lesser electrical activities (Manohar et al., 1999) and comparatively cleaner air. With reference to Fig. 6, in winter local aerosol loading in the then prevailing high stable conditions increases the $E$, the effect veining away as mixing increases in the atmosphere as temperature increases in Feb. and Mar. Further increase indicates a combined effect, with increase in thunderstorm activities in this region playing a role. The persistent high values in monsoon are explained earlier. Slightly lesser values in 
Oct. and Nov. than in pre-monsoon might be the outcome of lesser electrical activities and cleaner air existing over the region.

\section{Conclusions}

The study of diurnal variation of $E$ though caveat confirmative simultaneous observations, is to a high degree conclusive of certain facts and arises certain questions. Evidently it can be seen that space charge is as detrimental as conductivity as far as local effects on $E$ are concerned. Pollution related or otherwise generated aerosol, certainly decides conductivity at that place, in turn affects $E$, but the extent of influence is greatly dependent on atmospheric dispersion characteristics governed by temperature, wind, lapse rate and so on.

Reduction of $E$ in summer and enhancement in monsoon related to negative and positive space charge generation above ground based on the active physical processes at that time presents a valuable base and warrants thorough investigation, simultaneously interrogates as to what contribution the vast sandy deserts in the tropical belt those experience the weather conditions, will it remain local, regional or go up to global scale? Whole of African continent, south Asia and north Australia fit into the definition of "monsoon region", (Asnani, 1993) of which this station forms a tiny part, are under the influence of similar weather conditions and physical processes must leave their mark in the global level?

The global high of $E$ during northern hemisphere summer is coincident with the highest average during monsoon season here. It may be possible to connect cleaner tropical atmosphere here and a glimpse of the global activities. However, the author would strongly support the production of space charge due to increased evaporation as the cause enhancement in $E$ for it is very much felt that the level of aerosol concentration here then also appears to be quite higher than pristine levels.

Vonnegut et al. (1984) have tried to show the dependency of thunderstorm electrification on the space charge available beneath the cloud though not accepted at large. If so, space charge generation depending on the dryness or wetness of the ground might play a significant role to be a predictor of thunderstorm electrification in the premonsoon and post-monsoon periods. A comparative study of thunderstorms during these periods is planned. This does get an added significance considering the recent study of lightning characteristics at this observatory (Pawar and Kamra, 2002). These observations undoubtedly declare the special features of lightning occur here, rarely notified anywhere else.

Boundary layer processes such as stability, evaporation, wind drifting particles etc. have got a key role to play in fair weather measurements close to ground. Seasonal existence of such processes covering considerable area might even cross the local-regional limits to leave global signatures. To account for such products simultaneous observations over different land stations experiencing similar climatic conditions: polluted and pristine, and over oceans are very necessary.

Acknowledgments. I am thankful to Dr. A. K. Kamra and my colleagues who were involved in the data collection used in the present work. My special thanks are due to Mr. S. D. Pawar for extending a highly supportive hand for the work throughout.

\section{References}

Alderman, E. J. and E. R. Williams, Seasonal variation of global electric circuit, J. Geophys. Res., 101(D23), 29679-29688, 1996.

Anderson, R. V., The dependence of space charge spectra on aitken nucleus concentration, J. Geophys. Res., 87(C2), 1216-1218, 1982.

Asnani, G. C., Tropical Meteorology, Vol. I, 270 pp., published by G. C. Asnani, Pune, India, 1993.

Brown, C. J., The local variation of the earth's electric field, Terrestrial Magnetism and Atmospheric Electricity, 40, 413-424, 1935.

Chalmers, C. J., Atmospheric Electricity, pp. 168-169, 188, Pergamon Press, London, 1967.

Coffman, M. L., Charging grains of dust, J. Geophys. Res., 68, 1565-1566, 1963.

Delgado, M. L., D. E. García, D. F. de Pablo, and S. L. Rivas, Relationship between the atmospheric electric field (A.E.F.) and air pollution in the lower levels of the atmosphere, Proceedings of 12th ICAE, 365 pp., 2003.

Dhanorkar, S. and A. K. Kamra, Diurnal and seasonal variations of the small-, intermediate-, and large-ion concentrations and their contributions to polar conductivity, J. Geophys. Res., 98(D8), 14895-14908, 1993

Dhanorkar, S. and A. K. Kamra, Diurnal variation of ionization rate close to ground, J. Geophys. Res., 99(D9), 18523-18526, 1994.

Dhanorkar, S., C. G. Deshpande, and A. K. Kamra, Observations of some atmospheric electrical parameters in the surface layer, Atmospheric Environment, 23(4), 839-841, 1989.

Franke, M., The double periodic diurnal variation of the atmospheric electric potential or gradient as a consequence of exchange, Geophysica pura e applicata, 14, 1-12, 1949.

Harrison, R. G., Twentieth century atmospheric electrical measurements at observatories of Kew, Eskdalemuir and Lerwick, Weather, 58, 11-19, 2003.

Harrison, R. G. and K. L. Aplin, Mid-nineteenth century diurnal smoke concentrations at Kew, London, Atmospheric Environment, 36, 4037 4043, 2002.

Israel, H., The diurnal variation of atmospheric electric potential gradient, Meteor. Rdsch, 1, 200-204, 1948.

Israel, H., Atmospheric Electricity, vol. II, 350 pp., Israel program for scientific translation, Jerusalem, 1973

Israelsson, S., Report series in aerosol science no. 19, Dept. of Physics, Helsinki, Finland, 1991.

Israelsson, S., Measurement of surface-air space charge carried by dry winddriven dust, J. Atmos. Terr. Phys., 56, 1551-1556, 1994a.

Israelsson, S., The effects of wind and evaporation on space charge formation at the ground, J. Atmos. Terr. Phys., 56, 1-8, 1994b.

Kamra, A. K., Effect of wind on diurnal and seasonal variations of atmospheric electric field, J. Geophys. Res., 31, 1281-1286, 1969.

Kamra, A. K., Fair weather space charge distribution in the lowest two meters of atmosphere, J. Geophys. Res., 37, 4257-4263, 1982.

Kandalgaonkar, S. S. and G. K. Manohar, Variation in the atmospheric electric field at tropical station during 1930-1987, Advances in Atmospheric Sciences, 8, 99-106, 1991.

Kasemir, H. W., Current theory of atmospheric electric field III: the exchange generator, Archives of Meteorology and Geophysics Bioklim (A), 357-370, 1956.

Law, J., Ionization of the atmosphere near the ground in fair weather, Quarterly Journal of Royal Meteorological Society, 89, 107-121, 1963.

Mani, A. and B. B. Huddar, Studies of surface aerosols and their effects on atmospheric electric parameters, Pure and Applied Geophysics, 100, 154-156, 1972.

Manohar, G. K., S. S. Kandalgaonkar, and M. I. R. Tinmaker, Thunderstorm activity over India and the Indian southwest monsoon, J. Geophys. Res. 104(D4), 4169-4188, 1999.

Marshall, C. T., W. D. Rust, M. Stolzenburg, P. W. Roeder, and R. P. Krebhiel, A study of enhanced fair-weather electric fields occurring soon after sunrise, J. Geophys. Res., 104(D20), 24455-24469, 1999.

Muhleisen, R., J. Atmos. Terr. Phys., 8, 1956.

Muhleisen, R., Recent Advances in Thunderstorm Electricity, 213 pp., Clarendon Press, New York, 1958.

Pawar, S. D. and A. K. Kamra, Comparative measurements of atmospheric electric space charge density made with the filtration and Faraday cage technique, Atmospheric Research, 54, 105-116, 2000.

Pawar, S. D. and A. K. Kamra, Recovery curves of surface electric field after lightning discharges occurring between the positive charge pocket 
and negative charge centre in a thundercloud, Geophys. Res. Lett., 29, 2108, December 2002.

Prasad, B. S. N., K. Nagaraja, M. S. Chandrashekhara, L. Paramesh, and M. S. Madhava, Diurnal and seasonal variations of radioactivity and electrical conductivity near surface for a continental location Mysore (12 N, 76E), India, Proc. of 12th ICAE, 2003.

Raj, E. P. and P. C. S. Devara, Seasonal variation of Lidar-derived aerosol content in the lower layers of the atmosphere, Acta Meteorologica Sinica, 4, 113-119, 1990.

Raj, E. P., P. C. S. Devara, R. S. Maheshkumar, G. Pandithurai, and K. K. Dani, Lidar measurements of aerosol column content in an urban nocturnal boundary layer, Atmospheric Research, 45, 201-216, 1997.

Saha, S. K. and R. Ananthakrishnan, Diurnal and seasonal variation of thermal stability close to the surface at Poona in relation to air pollution, Indian Journal of Meteorology Hydrology and Geophysics, 27, 333-334, 1976.

Sapsford, H. B., Influence of pollution on potential gradient in Apia, Terr. Magn. Atmos. Elec., 42, 153-158, 1937.
Tammet, H. and S. Israelsson, Variation of fair weather atmospheric electricity at Marsta Observatory, Sweden, 1993-1998, J. Atmos. Solar-Terr. Phys., 63(16), 1693-1703, 2001.

Vonnegut, B., C. B. Moore, T. Rolan, J. Cobb, D. N. Holden, S. McWilliams, and G. Cadwell, Inverted electrification in thunderclouds growing over a source of negative charge, EOS, 65, 839, 1984.

Williams, E. R. and S. J. Heckman, The local diurnal variation of cloud electrification and global diurnal variation of negative charge on earth, $J$. Geophys. Res., 98(D3), 5221-5234, 1993.

Williams, E. R. et al., Contrasting convective regimes over the Amazon: implications for cloud electrification, J. Geophys. Res., 107(D20), 8082, doi:1029/1001JD000380, 2002.

Wilson, C. T. R., Investigation of lightning discharges and on the electric field of thunderstorms, Phil. Trans., A221, 73-115, 1920.

R. Latha (e-mail: latha@tropmet.res.in) 